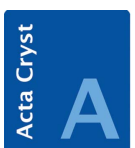

FOUNDATIONS

ADVANCES

\section{Symmetry, Spectroscopy, and Crystallography: The Structural Nexus. By Robert Glaser. Wiley-VCH, 2015. Pp. 328. Price GBP 80.00 (hardcover). ISBN 978-3-527- 33749-1.}

H. D. Flack¥

Chimie minérale, analytique et appliqúee, University of Geneva, Geneva, Switzerland

The content of this book comes from a graduate-level course entitled 'Special topics in structural chemistry and symmetry'. It is written in easy-to-follow modern-day English. Most of the illustrations are in black-and-white with a few colour pictures thrown in for good measure. The hardcover version of the book is well bound.

A nexus is a link or connection, a connected group, a network, or a central or focal point. However, the content of this book seems to flit from subject to subject in a uncoordinated manner and one is sometimes at a loss to know what particular point of interest the author wishes to stress. For example, history is mixed with a discussion of nomenclature. The text reads exactly like the content of a lecture, for which one is permitted a wider style of presentation than in a written document.

The presentation of symmetry and crystallography lack precision and clarity. If you wish to learn about either, this is not the book that you need. 